\title{
A Comparative Study on the Mechanical Properties of Arundo Donax Epoxy Composites with Bamboo Epoxy Composites
}

\author{
Prathap $\mathrm{K}^{[1]}$, Mr. Ravi Kumbar ${ }^{[2]}$ \\ ${ }^{[1]}$ PG Students,

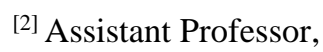 \\ Department of Mechanical Engineering \\ SJB Institute of Technology, Bangalore-560060.
}

\begin{abstract}
This paper aims to develop new polymer matrix composites using Arundo donax and bamboo in a powdered form as reinforcements. The laminates were prepared using conventional open mould hand layup method using magnetic stirrer. Thereafter tensile, flexural and impact tests were conducted and there results were compared with respective composition of the samples. There are many research's that have been carried out on bamboo epoxy composites and less research's on Arundo donax epoxy composites. The basic idea would proceed on the lines of initially using a few moulds of epoxy reinforced with Arundo donax and bamboo natural fiber in powdered form and stirring it well with magnetic stirrer, pouring it into the mould and allowing it to get naturally dry in the atmospheric air for the prescribed period. Both the fibers compositions are varied by $2 \%, 4 \% \& 6 \%$ and samples are cut based on the ASTM Standards. The different tests tensile, flexural and impact tests were to be conducted.
\end{abstract}

Keywords- Arundo donax, bamboo.

\section{INTRODUCTION}

With the technological advancements in today's world, the need of the hour calls for materials with lighter weight, higher strength, increased safety and better properties. This has led to the development of composite materials which have so far served the purpose.

Availability in natural fibers such as sugar cane, bamboo, jute, coconut shell and arundo donax are high.so I prefer Arundo donax because of its abundant availability .Arundo donax represent the slender like structures, It is a reed species .it grows in damp soil, either fresh or moderately saline and native to Mediterranean basin.it is been widely planted and naturalized in the mild temperature. Sub-tropical and tropical region.

bamboo species are native to warm and moist tropical and to warm temperate climates. However, many species are found in diverse climates, ranging from hot tropical regions to cool mountainous regions and highland cloud forests. In bamboo, as in other grasses, the internodal regions of the stem are usually hollow and the vascular bundles in the cross-section are scattered throughout the stem instead of in a cylindrical arrangement Bamboos include some of the fastest-growing plants in the world.
Here I have collected the bamboo waste from the wood industry and also using bamboo waste for preparation of the moulds.

\section{A. Why Use Composites?}

Composite materials (shortened to composites) are materials made from two or more constituent materials with significantly different physical or chemical properties, that when combined, produce a material with characteristics different from the individual components. The individual components remain separate and distinct within the finished structure. It is composed of two distinct phases: Matrix phase and reinforcing phase.

\section{1) Matrix phase}

The primary phase, having a continuous character, is called matrix. Matrix is more ductile and less hard phase. It holds the dispersed phase and shares a load with it.

Eg. Polymers, Metals, Ceramics

\section{2) Reinforcing phase}

The second phase is embedded in the matrix in a discontinuous form. This secondary phase is called reinforcing phase. Dispersed phase is usually stronger than the matrix.

Eg. Fibers, Particles, or Flakes

\section{A. Configuration of Composites}

Composites are composed of 


\section{a. Resin system}

The resins that are used in fibre-reinforced composites are polymers. All polymers exhibit an important common property in that they are composed of long chain like molecules consisting of simple repeating

units. Although there are many different types of resins in use in the composite industry, the majority of structural parts are made with three main types, namely polyester, vinyl ester and epoxy. The resin system used has good mechanical properties, good adhesive properties, toughness, resistance to environmental degradation.resin very good stiffness, toughness and heat resistant properties. The chemical name of LY556 epoxy resin is 2-(Chloromethyl) oxirane; 4 [2- (4hydroxyphyenl) propan2-yl]phenol and its chemical formula is $\mathrm{C} 18 \mathrm{H} 21 \mathrm{ClO} 3$

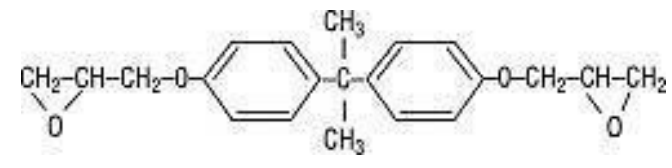

Figure 1 Chemical Structure of Epoxy

\section{B. Reinforcements}

One of the constituents in composite materials is the reinforcement, as the name suggests, the main function of this is to improve the overall mechanical properties of the composite. It is the discontinuous and strong phase of the composite. This reinforcement can be either in the particle form or fibrous form. It can be natural or man-made. Many materials are capable of reinforcing polymers. Most commercial

\section{Hardener}

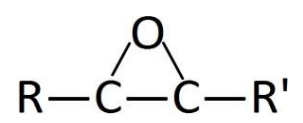

Figure 2 Epoxide Group

reinforcements however are man-made. Other composite reinforcements include carbon, aramid, polyethylene, polyester, silicon, silicon oxide and nylon. More specialized reinforcements for high strength and high temperature use include metals and metal oxides such as those used in aircraft or aerospace applications.

\section{a. Fillers}

Fillers are used to improve performance and reduce the cost of the composite by lowering the cost significantly more expensive resin and imparting benefits as shrinkage control, surface smoothness and crack resistance.

\section{b. Additives}

Additives are modifier ingredients that expand the usefulness of polymers, enhance the process ability or extend product durability.

\section{B. Epoxy}

The term 'epoxy' refers to a chemical group consisting of an oxygen atom bonded to two carbon atoms that are already bonded in some way. The simplest epoxy is a three-member ring structure known by the term 'alphaepoxy' or '1,2-epoxy'. The idealized chemical structure is shown in the figure below and is the most easily identified characteristic of any more complex epoxy molecule.

Epoxy resins are formed from a long chain molecular structure with reactive sites at either end. The epoxy molecule also contains two ring groups at its centre which are able to absorb both mechanical and thermal stresses better than linear groups and therefore give the epoxy The hardener, often an amine, is used to cure the epoxy by an 'addition reaction' where both materials take place in the chemical reaction. The chemistry of this reaction means that there are usually two epoxy sites binding to each amine site. The chemical name of the hardener HY951 is Triethylenetetramine and is chemical formula is $\mathrm{C} 6 \mathrm{H} 18 \mathrm{~N} 4$.

\section{Curing of Epoxy}

In general, uncured epoxy resins have poor mechanical, chemical and heat resistance properties. However, good properties are obtained by reacting the linear epoxy resin with suitable curatives to form three- dimensional cross-linked thermoset structures. This process is commonly referred to as curing. Curing of epoxy resins is an exothermic reaction and in some cases produces sufficient heat to cause thermal degradation if not controlled.

The composites industry has begun to recognize that the commercial applications of composites promise to offer much larger business opportunities than the aerospace sector due to the sheer size of transportation industry. Thus the shift of composite applications from aircraft to other commercial uses has become prominent in recent years.

The various reasons for the use of composites are due to

- To increase stiffness, strength and dimensional stability.

- To increase tough and impact strength.

- To increase heat deflection temperature.

- To increase mechanical damping.

- To reduce permeability to gases and liquids.

- To modify electrical properties.

- To reduce cost.

- To decrease thermal expansion.

- To increase chemical wear and corrosion resistance.

- To reduce weight.

- To maintain strength/stiffness at high temperatures while under strain conditions in a corrosive environment. 


\section{RESEARCH BACKGROUND}

Literally the term composite means a solid material that results when two or more different substances, each with its own characteristics, are combined to create a new substance whose properties are superior to those of the original components for any specific application. The term composite more specifically refers to a structural material within which a reinforcement material is embedded. And the engineering definition would also go alongside. A material system composed of a mixture or combination of two or more constituents that differ in form or material composition and are essentially insoluble in each other. In principle, composites can be fabricated out of any combination of two or more materials-metallic, organic, or inorganic; but the constituent forms are more restricted. The matrix is the body constituent, serving to enclose the composite and give it a bulk form. Major structural constituents are fibers, particulates, laminates or layers, flakes and fillers. They determine the internal structure of the composite. Usually, they are the additive phase.

\section{RESEARCH GAP}

V.Foire,T.scalici,A Valenza "Characterization of a new natural fiber from Arundo donax 1. as potential reinforcement of polymer composites". Aim of this paper to study arundo donax fiber as reinforcement in polymer composites it is worth note that lignin content of arundo donax fiber is greater than these of the other less common natural fibers..

Praveen kumar J, Sunder raj N, chandan H R ,Srivathsa marathe, Madhu $\mathrm{P}$ "natural fibers and its composites for engineering applications" this paper is very much useful for the information of natural fibers and its composites,evaluation of natural fibers and information about the classification of the natural fibers are done in this paper.

Vanchai Laemlaksakul "Physical and mechanical properties of particle board from bamboo waste" this reseach was to evaluate a technical feasibilities of making single layer experimental particle board panels from bamboo waste by converting bamboo into strips, which are used to make laminated bamboo furniture.

Ramachandran M , sahas Bansal, Pramod raichurkar "Experimental study of bamboo using banana and linen fiber reinforced polymeric composites" in this paper mechanical behaviour of natural fibers polymeric composites were presented. And also they are planning to carryout several tests with variety of composites and various size of the fibers of bamboo-banana epoxy composites.

Sahas bansal, M Ramachandran ,Pramod Raichurkar “ Comparative analysis of bamboo using jute and coir fiber reinforced polymeric composites" In this paper they compared a results of impact hardness,FTIR tests of different variation of bamboo epoxy resin and comparative study is import to notice the applications based on the results.
T.Gutu "A study on the mechanical strength properties of bamboo to enhance its diversification on its utilization" The research shows that bamboo can be used for construction material as well as well as furniture.

Jyun-kai,Huang and wen-bin young "The mechanical ,hygral \& interfacial strength of continuous bamboo". here bamboo fibers are treated with alkaline, then tensile strength \& young's modulus are increased.

Markus Ruggerberg,Ingo buyert \& Thomas speck "Structural \& mechanical design of tissue interfaces in the giant reed Arundo donax". Here the research shows abruph transition, remained almost constant across the interfaces between various tissues. The design principles found at interfaces between tissues in culm walls of Arundo dnax are discussed as an adaption strategy to mechanical loads, at different levels of hierarchy.

Av.Ratna Prasad ,K.Mohana Rao "Mechanical properties of natural fibers reinforced polyster composites,jowal,sisal \& bamboo". In this paper the experiments of tensile and flexural tests were carried out on composites made by reinforcing resin matrix. They have investigated a better mechanical properties of bamboo for fabrication of light weight components used in housing sector,automobile body building,packaging industry partition panels etc.

SAH Roslan;Z A RAsid,and MZ Hassan " Bamboo reinforced polymer composite A comprehensive review". This paper review paper summarized an overview of the bamboo, fiber extraction and mechanical the adhesion between bamboo and matrix is good because of alkali treatment. Alkali improves the bonding between the matrix and bamboo fibers.

Ku.H.Wang, N.Pattarcharyakoop, M.Trada “A review on the tensile properties of natural fiber reinforced polymer composites". This paper is review on the tensile properties of natural fiber reinforced polymer composites. In this paper it was discovered that rule of mixture predicted and experimental tensile strength of different natural fibers reinforced composites were very close to each other. Halpin-tsai equation was found to be the most effective equation in predicting the young's modulus of composites containing different types of natural fibers.

Hemalata jena,Arun kumar pradhan and mihir kumar pandit "studies on water absorption behaviour of bambooepoxy composite filled with cenosphere". This paper deals with the evaluation of water absorption properties of natural fiber . composites consisiting of bamboo fiber as reinforcement epoxy as matrix and cenosphere as particulate filler at different environmental conditions.

V.Fiore , L Butta, K.scaffar, A.Valenza,A.piorotta "PLA based biocomposites reinforced with Arundo donax fillers". In this work,for the firsttime, the influence of content and size of ADF on morphology and on the mechanical and thermal properties of PLA-ADF composites was evaluated.

Naheed saba, mohammad jawaid, Othman Y althoman MT 
Paridh and Azman Hassan "Recent advances in epoxy resin natural fibers reinforced epoxy composites and their applications". Present review article designed to be comprehensive source of recent literature on the epoxy structure ,synthesis modified epoxy, bio-epoxy resin, and its applications. The review article also aims to cover the recent advances in natural fiber-based epoxy composites and nano composites research study, including manufacturing techniques and their different industrial applications.

\section{OBJECTIVE AND METHODOLOGY}

To Investigate and analyze the mechanical properties of a composite material using bamboo fiber and arundo donax fiber. To explore the processing feasibility of both bamboo fiber and Arundo donax fiber. To carry out a systematic study of the influence of processing parameters on the mechanical properties of bamboo and arundo donax fibers. To make arundo donax epoxy composites utilization more by reducing bamboo fiber utilization.

\subsection{MATERIALS}

Following are the materials used

\section{Epoxy Resin: LY556}

2. Hardener: HY951

3. Arundo donax and Bamboo fiber in powdered form

4. Releasing Agent: Mansion Wax

5. Sealant: Anabond Silicone Sealant

6. Cleaning Agent: Acetone

7. MWCNT Dispersal Medium: Acetone.

\subsection{PREPARATION OF MOULDS}

1.The mould plates are cleaned with acetone.

2. Mansion wax is applied to mould for easy removal of the mould after curing.

3. Spacer plates are inserted based on the thickness of casting (here $3 \mathrm{~mm}$ ) of the required dimensions between the two mould plates and sides of the mould are sealed with silicon sealant.

The basic idea would proceed on the lines of initially using a few moulds of epoxy reinforced with both the Arundo donax and Bamboo fibers separately and stirring it well with magnetic stir, pouring it into the mould and allowing it to get naturally dry in the atmospheric air for the prescribed period.

It is to be noted that different moulds would have different percentage of Arundo donax and Bamboo natural fiber in powdered form reinforced into the epoxy.

Steps that are followed for preparation of Arundo donax and Bamboo fiber into powdered form are shown below.

Both the Arundo donax and Bamboo natural fibers cut down and are dried in sun for $80 \%$ removal of moisture and it is chopped into small pieces.

And both the Arundo donax and Bamboo fibers are grinded into powdered form, further this powder is allowed to air dry on the pan for 30 min to reduce the temperature.
This dried Arundo donax and bamboo fiber powder becomes a fine powder. Further they are used as reinforcement for preparation of composite laminates.

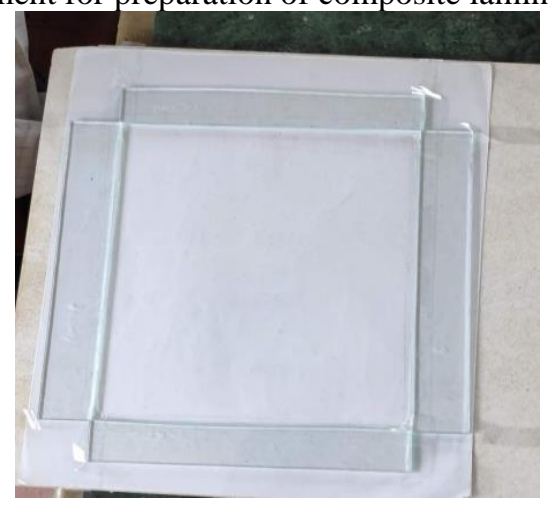

Figure 1 Finished mould plate

\subsection{PREPARATION OF CASTINGS}

1. Two beakers are washed with acetone and allowed to dry

2. As per the ratio of resin and hardener, that is 100:20, the weight of resin and Hardener is calculated. Resin is weighed in one beaker and hardener in the other.

3. The hardener is added to the beaker containing resin. It is mixed thoroughly for about5 minutes.

4. The resin-Hardener mixture is poured into the prepared mould.

5. The mould is allowed for 48 hours for curing and the mould is released.

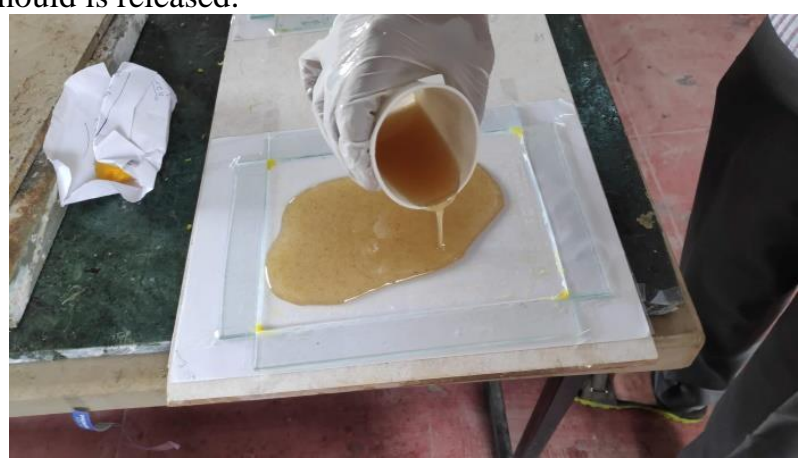

Figure 2 Pouring of Resin Hardener Mixture

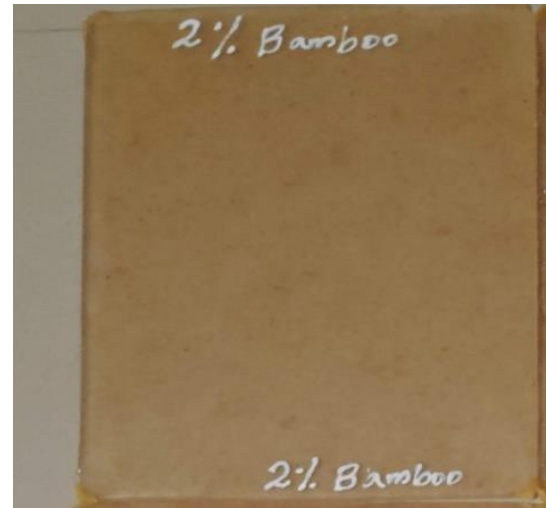

Figure 3 Removed Mould 
Specimens were cut according to ASTM Standards using fabric cutting machine.

\begin{tabular}{|c|c|c|}
\hline Serial NO. & Test Type & ASTM Standard \\
\hline 1 & Tensile & D638 \\
\hline 2 & Bending & D790 \\
\hline 3 & Impact & D256 \\
\hline
\end{tabular}

Table 1 ASTM standards

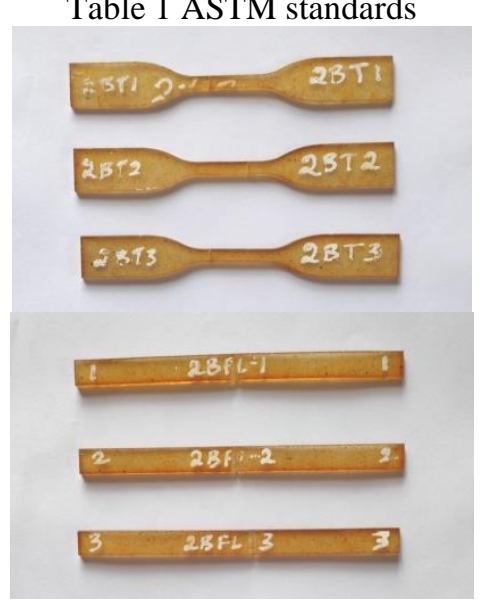

Figure 4 Tensile and bending Samples

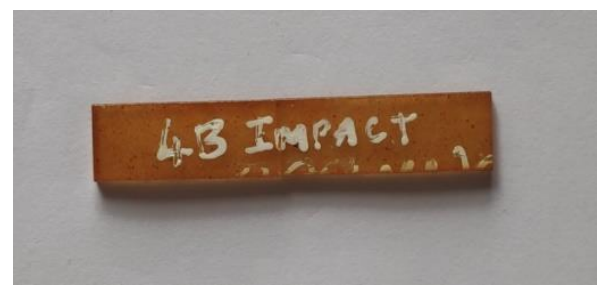

Figure 5 Impact Sample

\section{RESULTS AND DISCUSSION}

In this chapter the results of the study are presented and discussed with reference to the aim of the study. Various tests that are mentioned in the previous chapter are discussed below. This chapter gives in depth details of the project with reference to the tests performed.

\subsection{TENSILE STRENGTH RESULTS}

The samples which epoxy resin reinforced with $2 \%, 4 \%$ \& $6 \%$ Bamboo fiber and Arundo donax fiber were cut from the respective moulds. Six specimens namely $2 \mathrm{BT}$, 4BT,6BT,2ADT,4ADT \& 6ADT and were subjected to Tensile Test. The Result of the Specimen 6BT shows the maximum Tensile strength among the three Bamboo specimens. The Result of the Specimen 2AD shows the maximum Tensile strength among the three Arundo donax specimens. The stress vs strain results and tensile test results of this specimen are shown below.

Maximum load $=1.0849 \mathrm{kN}$

Load at break $=0.21699 \mathrm{kN}$

Young's Modulus: 41.5329 Gpa

\begin{tabular}{|c|c|c|c|}
\hline $\begin{array}{c}\text { Bamboo } \\
\text { specimens }\end{array}$ & $\begin{array}{c}\text { TensileStrength } \\
\left(\mathrm{N} / \mathrm{mm}^{2}\right)\end{array}$ & $\begin{array}{c}\text { Arundo donax } \\
\text { specimens }\end{array}$ & $\begin{array}{c}\text { TensileStrength } \\
\left(\mathrm{N} / \mathrm{mm}^{2}\right)\end{array}$ \\
\hline 2BT & 65.261 & 2ADT & 67.166 \\
\hline 4BT & 65.085 & 4ADT & 60.351 \\
\hline 6BT & 65.353 & 6ADT & 61.808 \\
\hline
\end{tabular}

Table 2 Tensile test results

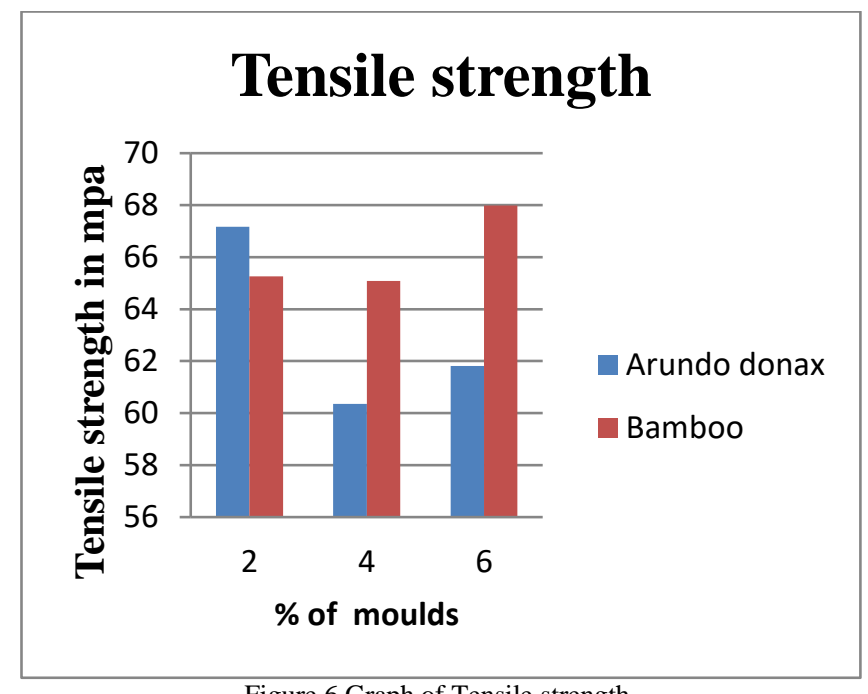

Figure 6 Graph of Tensile strength

Tensile test was conducted for both the Arundo donax and bamboo epoxy composites, above tables and graphs shows the Tensile strength of all the samples with different composition, from the experiment we can observe that Tensile strength of sample 4 with $2 \% \mathrm{AD}+98 \%$ matrix is more when compared to $2 \% \mathrm{~B}+98 \%$ matrix and $6 \% \mathrm{~B}+94 \%$ Matrix has more tensile strength as we can observe on the graph above, which can be used in different application.

\subsection{FLEXURAL STRENGTH RESULTS}

The samples which epoxy resin reinforced with $2 \%, 4 \% \&$ $6 \%$ Bamboo fiber and Arundo donax fiber were cut from the respective moulds. Six specimens namely $2 \mathrm{BF}$, $4 \mathrm{BF}, 6 \mathrm{BF}, 2 \mathrm{ADF}, 4 \mathrm{ADF} \& 6 \mathrm{ADF}$ and were subjected to Flexural Test. The Result of the Specimen 2BF shows the maximum Flexural strength among the three Bamboo specimens. The Result of the Specimen 4ADF shows the maximum Flexural strength among the three Arundo donax specimens. The stress vs strain results and Flexural test results of this specimen are shown below.

Ultimate load $=1.0849 \mathrm{kN}$

Maximum displacement $=0.21699 \mathrm{kN}$

\begin{tabular}{|c|c|c|c|}
\hline $\begin{array}{c}\text { Bamboo } \\
\text { specimens }\end{array}$ & $\begin{array}{c}\text { Flexural Strength } \\
2 \\
\left.\mathrm{~N} / \mathrm{mm}^{2}\right)\end{array}$ & $\begin{array}{c}\text { Arundo } \\
\text { donax } \\
\text { specimens }\end{array}$ & $\begin{array}{c}\text { Flexural Strength } \\
2 \\
\left(\mathrm{~N} / \mathrm{mm}^{2}\right)\end{array}$ \\
\hline $2 \mathrm{BF}$ & 65.261 & 2ADF & 67.166 \\
\hline $4 \mathrm{BF}$ & 65.085 & 4ADF & 60.351 \\
\hline $6 \mathrm{BF}$ & 65.353 & $6 \mathrm{ADF}$ & 61.808 \\
\hline
\end{tabular}

Table 3 Flexural test results 


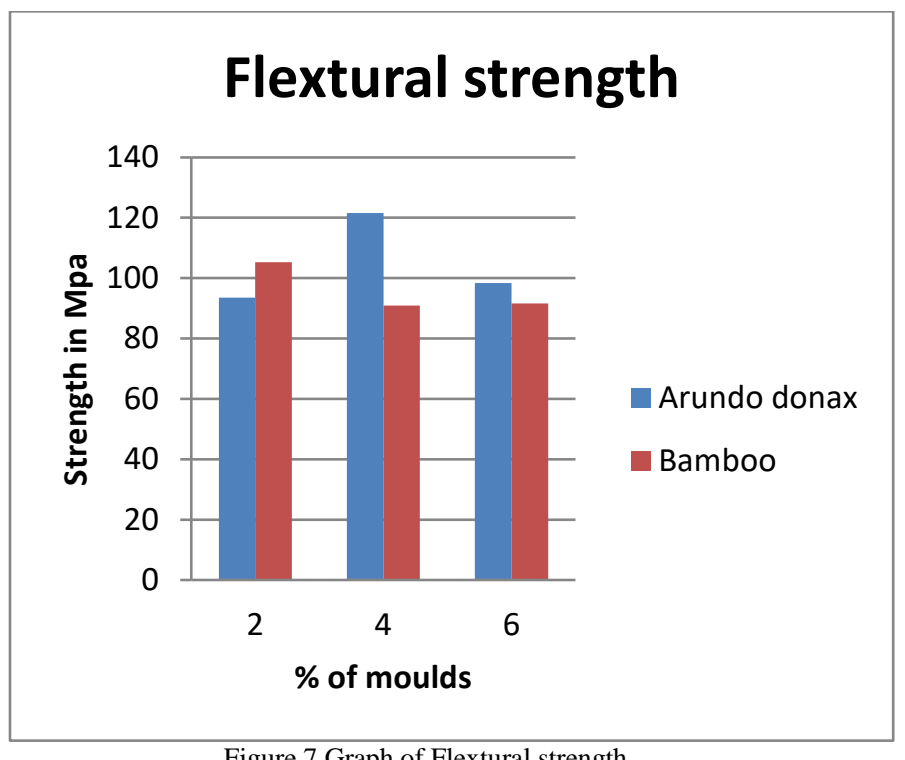

Figure 7 Graph of Flextural strength

Flexural test was conducted for both the Arundo donax and bamboo epoxy composites, above tables and graphs shows the Flexural strength of all the samples with different composition, from the experiment we can observe that Flexural strength of Arundo donax are better than Bamboo composites. sample 5 containing $4 \% \mathrm{AD}+96 \%$ Matrix has more Flexural strength as we can observe on the graph above, which can be used in different applications.

\subsection{IMPACT STRENGTH TEST RESULTS}

Impact testing is a method of determining the impact(high rate of load) resistance of any given material. A pivoting arm is raised to a specific height from rest and then released. The arm swings down hitting a the sample, breaking the specimen. The energy absorbed by the sample is calculated from the height the arm swings to after hitting the sample.

\begin{tabular}{|c|c|c|c|}
\hline $\begin{array}{c}\text { Bamboo } \\
\text { specimens }\end{array}$ & $\begin{array}{c}\text { Izod impact } \\
\text { strength in } \mathrm{kJ} / \mathrm{m}^{2}\end{array}$ & $\begin{array}{c}\text { Arundo } \\
\text { donax } \\
\text { specimens }\end{array}$ & $\begin{array}{c}\text { Izod impact } \\
\text { strength in } \mathrm{kJ} / \mathrm{m}^{2}\end{array}$ \\
\hline $2 \mathrm{BI}$ & 6.27 & 2ADI & 7.99 \\
\hline 4BI & 8.51 & 4ADI & 7.37 \\
\hline $6 \mathrm{BI}$ & $639+$ & 6ADI & 9.68 \\
\hline
\end{tabular}

Table 4 Experimental data of Impact test

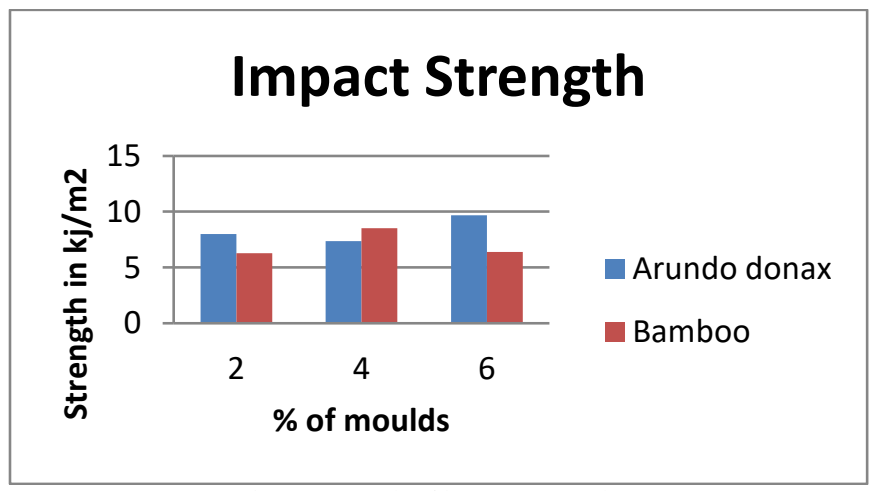

Figure 8 Graph of impact strength
For PMC's impact strength is very less when compared to MMC's. Impact Test was conducted for all the Arundo donax and Bambooo epoxy composites, above table and graph shows the data of the experiment, from the experiment we can observe that Arundo donax composites shows better impact strength than Bamboo epoxy composites. A sample containing 6\%Ad+94\% Matrix has more impact strength as we can observe on the above graph.

\section{CONCLUSIONS}

In this project we have done a mechanical character analysis on arundo donax fiber with epoxy composites in comparision with bamboo epoxy composites. By doing this project we have gained good knowledge about natural fibers and the mechanical tests were conducted and the results were included with this project report. By seeing the test results we here by conclude that the arundo donax fiber with epoxy resin composites has similar mechanical properties with bamboo epoxy composites.so arundo donax composites can easily replace the several applications of bamboo composites.

\section{REFERENCES}

[1] V.Foire, T.scalici, A Valenza "Characterization of a new natural fiber from Arundo donax 1. as potential reinforcement of polymer composites". University of Palermo, 90128 palermo Italy.

[2] Praveen Kumar J, Sunder Raj N, Chandan H R ,Srivathsa Marathe, Madhu P "natural fibers and its composites for engineering applications" volume-6, issue-1, jan-2018.

[3] Vanchai Laemlaksakul "Physical and mechanical properties of particle board from bamboo waste" World Academy Of Sciences, Engineering And Technology, International Journal Of Chemical, Molecular, Nuclear, Materials And Metallurgical Engineering Vol;4, No;4, 2010

[4] Ramachandran M , sahas Bansal, Pramod raichurkar "Experimental study of bamboo using banana and linen fiber reinforced polymeric composites.

[5] Sahas bansal, M Ramachandran „Pramod Raichurkar " Comparative analysis of bamboo using jute and coir fiber reinforced polymeric composites. MPSTME, SVKM'S NMIMS University, Dhule 425405, Maharastra, India, 10 april 2016

[6] Markus Ruggerberg, Ingo burgert \& Thomas speck "Structural \& mechanical design of tissue interfaces in the giant reed Arundo donax. Faculty of biology, plant biomechanics group, botanic garden of the university, Freiburg, Germany. J.R. Soc. Inteface (2010)7,499-506.

[7] Av.Ratna Prasad ,K.Mohana Rao "Mechanical properties of natural fibers reinforced polyster composites,jowal,sisal \& bamboo. Department of Mechanical Engineering, V R Siddhartha Engineering College, Vijayawada 520 007, A P, India

[8] SAH Roslan;Z A RAsid,and MZ Hassan “ Bamboo reinforced polymer composite_A comprehensive review. To cite this article: S A H Roslan et al 2018 IOP Conf. Ser.: Mater. Sci. Eng. 344 012008.

[9] Hemalata jena,Arun kumar pradhan and mihir kumar pandit "studies on water absorption behaviour of bamboo-epoxy composite filled with cenosphere Journal of Reinforced Plasticsand Composites2014, Vol. 33(11)10591068! TheAuthor(s)2014Reprintsandpermissions:sage pub.co.uk/journalsPermissions.navDOI:10.1177/0731684414523 325jrp.sagepub.com. 
[10] V.Fiore, L Butta, K.scaffar, A.Valenza,A.piorotta "PLA based biocomposites reinforced with Arundo donax fillers. PII: S01448617(14)001374DOI:http://dx.doi.org/doi:10.1016/j.carbpol.2014 02.016Reference: CARP 8583

[11] Bhavna Sharma , Ana Gatóo, Maximilian Bock, Michael Ramageengineered "Bamboo For Structural Applications department Of Architecture", University Of Cambridge, Cambridge, Uk Construction And Building Materials 81 (2015) 66-73. 